\title{
Quantifying The Significance of Distance to Temporal Dynamics of Covid-19 Cases in Nigeria Using a Geographic Information System
}

\author{
Ifeyinwa Sarah Obuekwe ${ }^{1,2 *}$ (D), Umar Saleh Anka ${ }^{1,3}$ (D), Sodiq Opeyemi Ibrahim ${ }^{1,3}$ (iD), \\ Usman Ahmad Adam ${ }^{4}$ \\ ${ }^{1}$ Nigerian Environmental Society, Nigeria \\ ${ }^{2}$ Department of Microbiology, Faculty of Life Sciences, University of Benin, Benin City, Edo \\ State, PMB. 1154, Nigeria \\ ${ }^{3}$ Department of Geography, Faculty of Earth and Environmental Sciences, Bayero University, \\ Kano State, Nigeria \\ ${ }^{4}$ Department of Geography, Sa'adatu Rimi College of Education, Kumbotso, Kano, Nigeria
}

Received 16 December 2020 /Revised 8 April 2021 /Accepted 17 April 2021 /Published 25 April 2021

\begin{abstract}
The coronavirus disease 2019 (COVID-19) is caused by a new strain of coronavirus that spreads primarily by close contact. Although Nigeria adopted lockdown measures, no defined strategies were used in setting the distance threshold for these lockdowns. Hence, understanding the drivers of COVID-19 is pivotal to an informed decision for containment measures in the absence of vaccines. Spatial and temporal analyses are crucial drivers to apprehending the pattern of diseases over space and time. Thus, this study aimed to quantify the significance of distance to the temporal dynamics of COVID-19 cases in Nigeria using the Geographic Information System. Incremental spatial autocorrelation was used to analyze datasets of each month in ArcGIS. March, April, May, and June exhibited patterns with no significant peaks, while July and August exhibited patterns with two statistically significant peaks. The first and second peaks of July were 301,338.39 and 365,947.83 meters, respectively, while August was 301,338.39 and 336,128.09 meters, respectively. Therefore, a significant difference in the clustering of COVID19 over distances between July and August was established. This indicated that progression in the spread of the virus increased the virus's spatial coverage while the distance of risk of exposure decreased. This study's findings could be utilized to establish maximum movement restriction areas to contain the spread of COVID-19.
\end{abstract}

Keywords: Distance; Incremental spatial autocorrelation; Covid-19; Disease; Nigeria

\section{Introduction}

COVID-19 is a respiratory disease that emerged in late 2019 caused by a new coronavirus that presents pneumonia-like symptoms. Therefore, it has high transmission competence and spreads primarily when people are in close contact (Dhama et al., 2020).

*Corresponding author.

Email address : ifeyinwa.obuekwe@uniben.edu (Ifeyinwa Sarah Obuekwe) 
COVID-19 is causing an ongoing pandemic in many countries and territories, and therefore, it is a global health crisis (Mckee \& Stuckler, 2020).

Infected people are accommodated and isolated in designated health facilities across the world for treatment. In the absence of a vaccine to prevent or aid speedy recovery, a significant concern is that, as the number of infected people increases, the healthcare system will be overwhelmed (Murray et al., 2020). Nevertheless, efforts to prevent further spreading are ongoing in many nations as vaccines, and antiviral drugs are awaited.

In response to the worldwide COVID-19 outbreak, many sub-Saharan Africa countries have implemented strict lockdown measures to emulate high-income countries to contain the spread of the virus (Teachout \& Zipfel, 2020). However, severe restrictions placed on people's travel may impact different livelihoods, especially the world's poorest people (Woodhill, 2020). Gradually, the impact of the lockdown is unfolding and remains largely guesswork.

Despite the likelihood of severe impact of lockdown on livelihoods, there is no adequate information to help guide the threshold with which movement restriction can be placed. Details about places where cases may arise concerning identified cases could help enhance movement restriction decisions. Wang et al. (2021) claimed that the temporal trends of COVID-19 across space require deliberation when considering lifting lockdown. This makes the need for a timely knowledge of the temporal and spatial patterns of COVID-19 transmission. However, knowledge of the geographical mean distances between the locations of cases and the direct estimation of distances between sequential cases requires both the recognition of cases and their infectors (Salje et al., 2016). Such contact tracing efforts are nearly impossible because of two major restrains, cost and time. Thus, limited data hinders the ability to characterize the space and time scales where cases tend to occur.

Estimating mean transmission distances have been possible previously only in situations where there is available data for most cases in a transmission network or detailed epidemiological data on who infected whom (Memish et al., 2014; Marziano et al., 2017; Yang et al., 2020). In the absence of data on where COVID-19 cases were discovered in Nigeria, there is the need to seek alternatives that can help in decision-making before the spread of the virus is beyond management capacity. Hence, this study's novelty was that it demonstrated an approach to quantify the significance of temporal dynamics in the mean transmission distance of recorded COVID-19 cases in Nigeria. This was based on the use of geographic information system 
software, data of the monthly COVID-19 recorded cases, and the coordinates of the capital of the thirty-six (36) States in Nigeria and the Federal Capital Territory. This study aimed to quantify the significance of distance to the temporal dynamics of COVID-19 cases in Nigeria using the Geographic Information System.

\section{Methods}

\subsection{Description of Study Area}

Nigeria covers an area of 923,769 square kilometers, and it's bordered by different countries on the north, south, east and west. On the north is Niger and Chad, south is Gulf of Guinea while the east and west are Cameroon, Benin and Niger respectively (National Bureau of Statistics, 2011).

\subsection{Study Area Ecosystem}

The coast of Nigeria is surrounded by flowering trees in marshes which are traversed by estuaries and rivers as well as the great Niger basin (National Bureau of Statistics, 2011).Eastwards however, lie successive belts of tropical rain forests and the undulating plateau, rising from 609.6 meters on the average to 1,828.8 meters. Grassland vegetation interspersed with trees and shrubs is seen midway north of the country however, this stops at the north-east desert which is the grassy coast region.

River Niger receives its Benue counterpart at Lokoja, and from there flows into the Atlantic Ocean for about 547 kilometers. Its tributaries include include Sokoto, Kaduna and Anambra Rivers (National Bureau of Statistics, 2011). However, the Benue River is fed by two rivers namely Katsina-Ala and Gongola. Nigeria has other rivers which include Cross River, Benin and Ogun rivers (National Bureau of Statistics, 2011).

\subsection{Study Area Population and Geopolitical Zones}

The population of Nigeria in mid-year of 2020 is estimated at 206,139,589 people based on United Nation data (Worldometer, 2020). Nigeria practices democratic system of government and each state and the Federal Capital Territory has their elected officials. The elected officials are from political parties within the country. 
Ifeyinwa Sarah Obuekwe et al. / Geosfera Indonesia 6 (1), 2021, 40-54

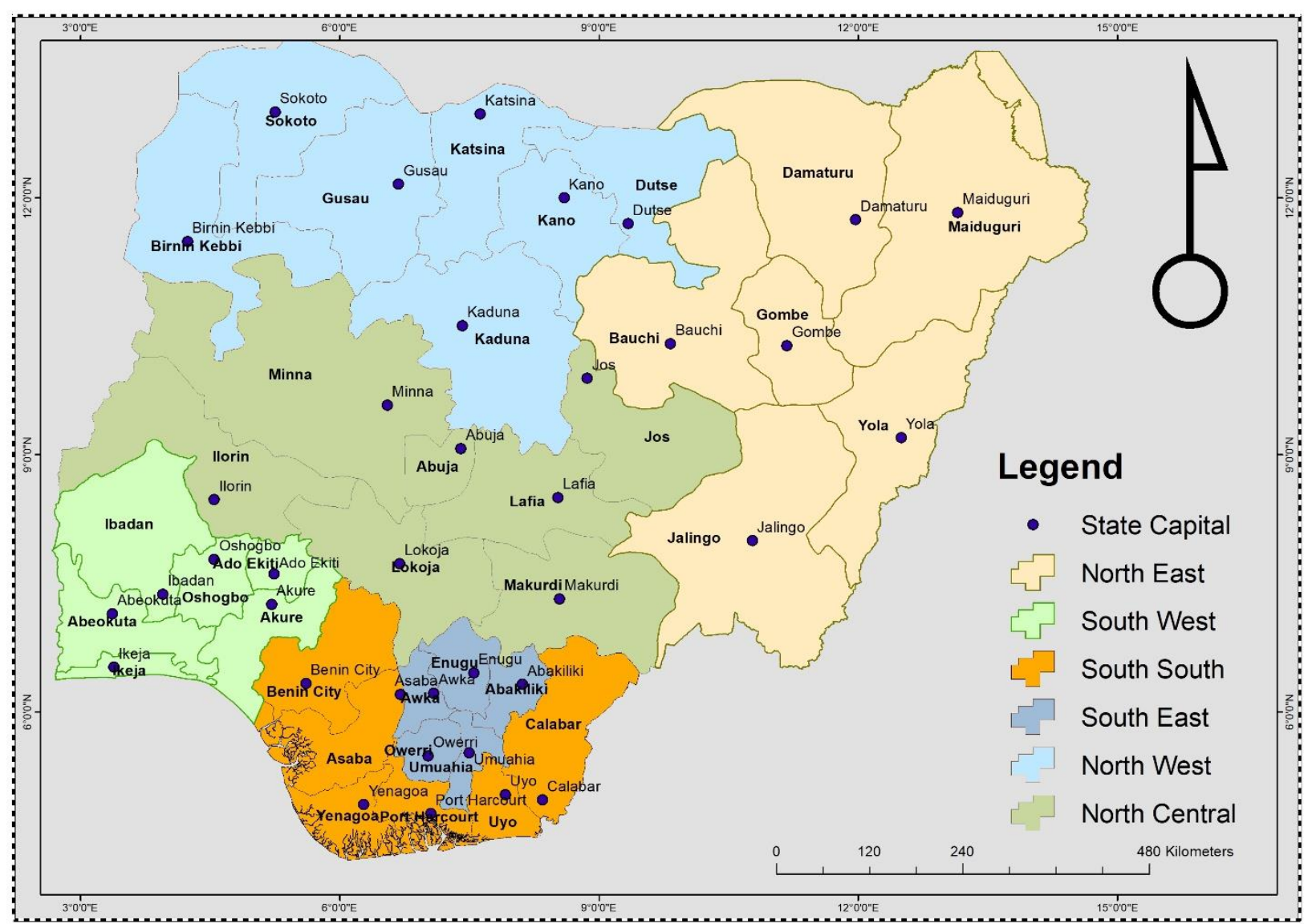

Figure 1. Nigeria 36 states and the federal capital territory in their geopolitical zones (GIS Lab

Geography Department, 2020)

\subsection{Research Design}

The study was an explorative research. Due to the newness of COVID-19, explorative research has been adopted in several studies (Scarpone et al., 2020) as it offers researchers the opportunity to study a problem that has not been thoroughly studied in the past.

\subsection{Data and Sources of Data}

The study made use of publicly available COVID-19 and spatial datasets. The COVID-19 dataset used include monthly recorded cases from March to August, 2020. The data were downloaded from Nigeria Centre for Disease Control (2020) website (https://covid19.ncdc.gov.ng/). This data is updated once a day (at 23:59 WAT).The spatial data used for this study was shapefile of Nigeria including states and coordinates of state capitals. The spatial data were sourced from the Geographic Information System Laboratory, Department of Geography Bayero University, Kano. 


\subsection{Data Analysis}

The monthly COVID-19 recorded cases for the 36 states and the federal capital of Nigeria were subjected to incremental spatial autocorrelation analysis in ArcGIS 10.5 with the use of a conceptualized fixed distance. The incremental spatial autocorrelation analysis work in such a way that it calculates the Moran's I index and z score of a single data set at multiple distances. Z-score is a standard deviation which measures the distance of a raw score from the mean. Also, the rule of thumb for pattern analysis like spatial autocorrelation is that the $\mathrm{z}$-score and p-values obtained determine the confidence level which can be used to accept or reject a null hypothesis. Hence, the threshold for determining the confidence level of a $\mathrm{z}$-score and $\mathrm{p}$-value is shown in Table 1.

Hence, analyzed fixed distances were derived from each of the possible distance between a data point (a state capital) and all other data points (other state capitals). As in the case of this study, Moran's I index was run for all the possible distances that existed between the 36 states and the federal capital of Nigeria. Instead of using the Moran's I index value, the distance was used to plot the $\mathrm{z}$ scores. This enabled a standardized distance-based comparison of statistical significance using the threshold in Table 1. Larger positive $\mathrm{z}$ scores indicate high significant clustering (Table 1). Thus, in each of the plots, distances of the first peak and maximum peak were identified, as the first peak indicates lower statistically significant clustering while the maximum peak indicates the distance that clustering or spatial autocorrelation was of most statistical significance in the data set. Also, different colors were used to indicate the z-scores each distant point belong to as well as which distance is characterized as a peak.

Table 1. Critical p-values and z-scores for Different Confident Levels (Moran, 1948)

\begin{tabular}{ccc}
\hline z-score (Standard Deviations) & p-value (Probability) & Confidence Level (\%) \\
\hline$<-\mathbf{- 1 . 6 5}$ or $>+\mathbf{1 . 6 5}$ & $<0.10$ & 90 \\
$<\mathbf{- 1 . 9 6}$ or $>+\mathbf{1 . 9 6}$ & $<0.05$ & 95 \\
$<\mathbf{- 2 . 5 8}$ or $>+\mathbf{2 . 5 8}$ & $<0.01$ & 99 \\
\hline
\end{tabular}

Furthermore, the distance of each state capital to other state capital and the federal capital was first obtained in ArcGIS via point distance analysis. The obtained distance was then exported to excel where the mean was determined. In addition, bar graph was used to visualize the mean distance and distances where Covid 19 clustering were significant. Afterwards, 
distances with significant peaks was compared with the mean distance of each state capital and the Federal Capital to other state capital and Federal Capital. The flowchart of the methodology for the study is summarized in Figure 2.

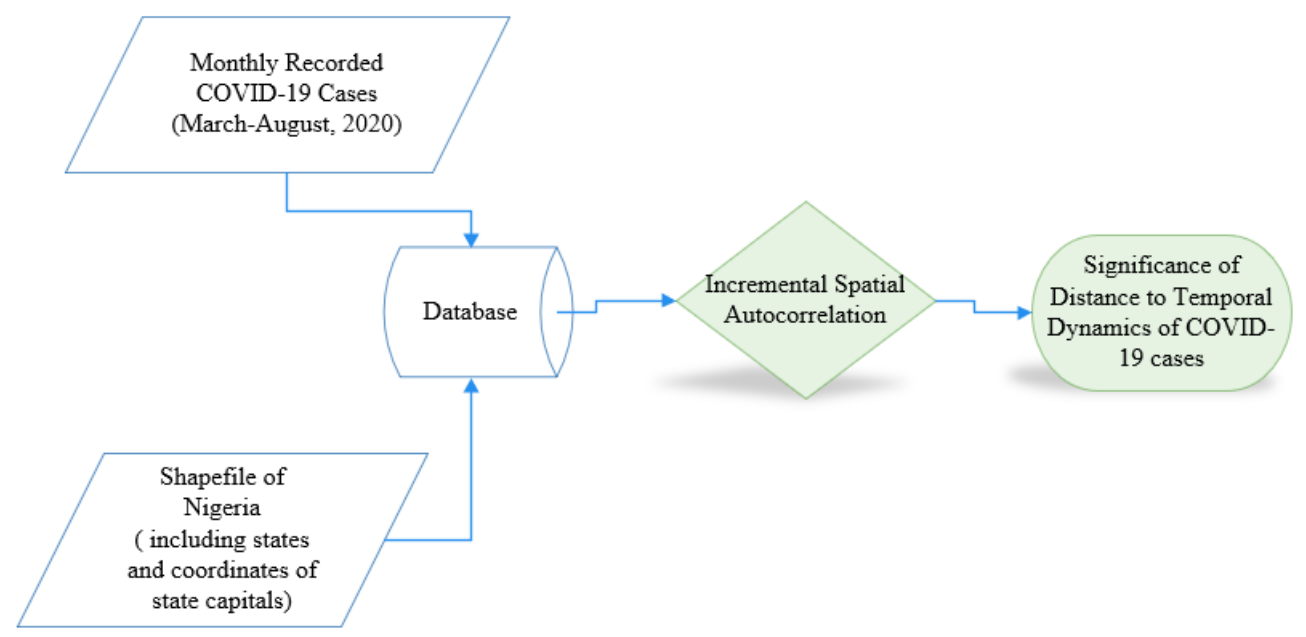

Figure 2. Flowchart of the method of the study

\section{Results and Discussion}

After the index case of COVID 19 in February, by the end of March, Lagos has recorded 62 cases and was the highest state in Nigeria with recorded cases (Figure 3). This was followed by the Federal Capital Territory, which had a recorded 9-28 victims. South Western states that were closer to Lagos were also observed to have recorded 4-8 victims. The cases recorded in Kaduna, Bauchi, Ekiti, Edo, Benue, Enugu, and Rivers were within 1-3 while the other states had no recorded cases. Alkhamis et al. (2020) also observed that after about a month from the first reported case of COVID-19 in Kuwait, the size was small despite sporadic infections. Gayawan et al. (2020) also stated that COVID-19 initially had a slow spread across Africa, only for the situation to escalate in the last week of March.

In April, although Lagos still had the highest recorded cases, the spread of the virus in the north within the addition of one month is a course to worry about (Figure 5). Kano state that had no recorded case in March had the same range of 77-219 recorded cases with the Federal Capital Territory. This implies that the rate of spread in the north was high in April, despite the Federal Government imposing a lockdown on Lagos, Ogun, and Abuja on March 30, 2020. The high 
Ifeyinwa Sarah Obuekwe et al. / Geosfera Indonesia 6 (1), 2021, 40-54

spread indicates the lockdown was not as effective as that of China's strict lockdown (Prem et al., 2020).

May's spread exceeds that of March and April combined with Kano having more recorded cases than the Federal Capital Territory. Despite the lockdown, border porosity, which is an issue in most African countries (Okunade \& Ogunnubi, 2019), makes it hard to restrict mobility effectively. The ability to contain human mobility has been an issue worldwide as Migrant workers and travelers have been the mostly affected and responsible for spreading the virus (Kuwait Government Online, 2020; Gayawan et al.,2020).

There was an increase in the spread of COVID-19 between June and July. However, the range of increase in Abuja and Oyo for July exceeded Kano, Edo, Delta, and Rivers State (Figure 9 and Figure 11). It was also observed that Cross River was the last state to record the COVID19 case in Nigeria (Figure 11). As of August, all the states in Nigeria had a recorded case of more than 52 except Kogi. Also, states like Kano, Kaduna, Plateau, Oyo, Ogun, Ondo, Edo Delta, River Lagos, and the Federal Capital Territory each had more than 1000 recorded cases.

The variability in the monthly pattern of COVID-19 that can be observed from 3,5,7,9, 11 and 13 was how clustered the COVID-19 cases are. In March, the first cluster was observed where states around Lagos had high recorded cases (Figure 3). The cluster that stood out in April, May, and June was that of Kano state and the state around it. By July and August, more cases have been recorded in most states, thus resulting in a smaller number of states forming a cluster. Studies of Wang et al. (2021); Kim \& Castro (2020), and Xie et al. (2020) also observed spatial clustering about COVID-19 distribution at a national scale. 
Ifeyinwa Sarah Obuekwe et al. / Geosfera Indonesia 6 (1), 2021, 40-54

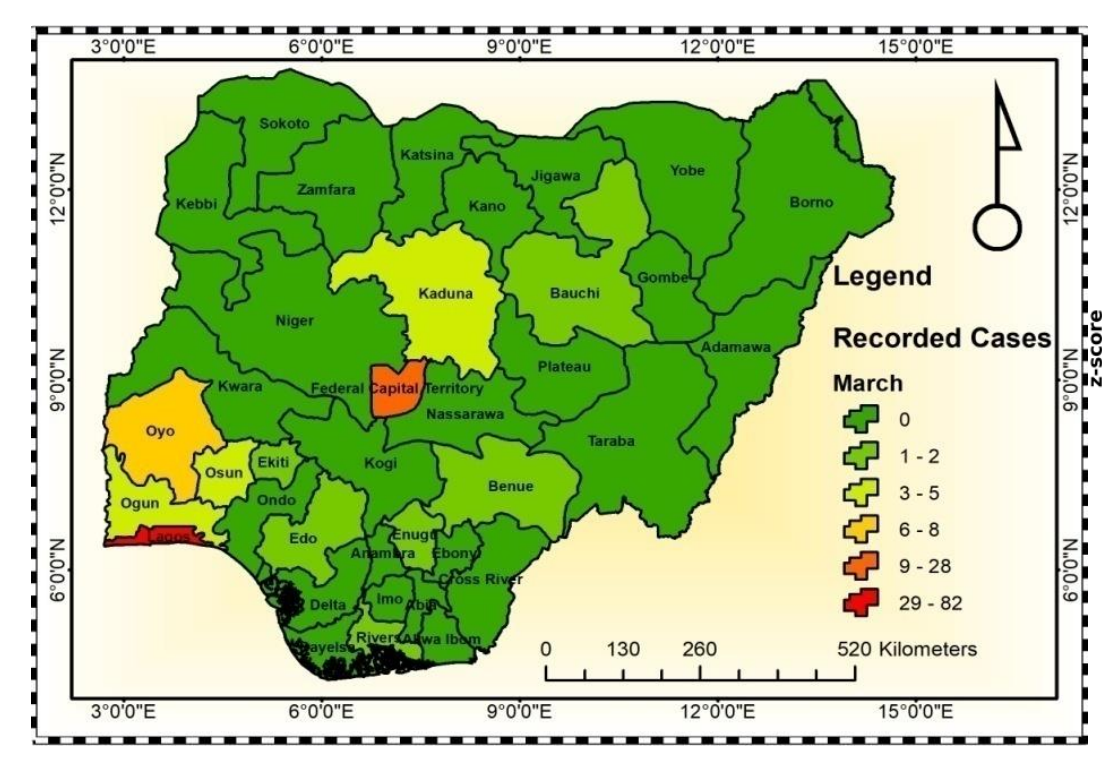

Figure 3. Covid 19 recorded cases-march

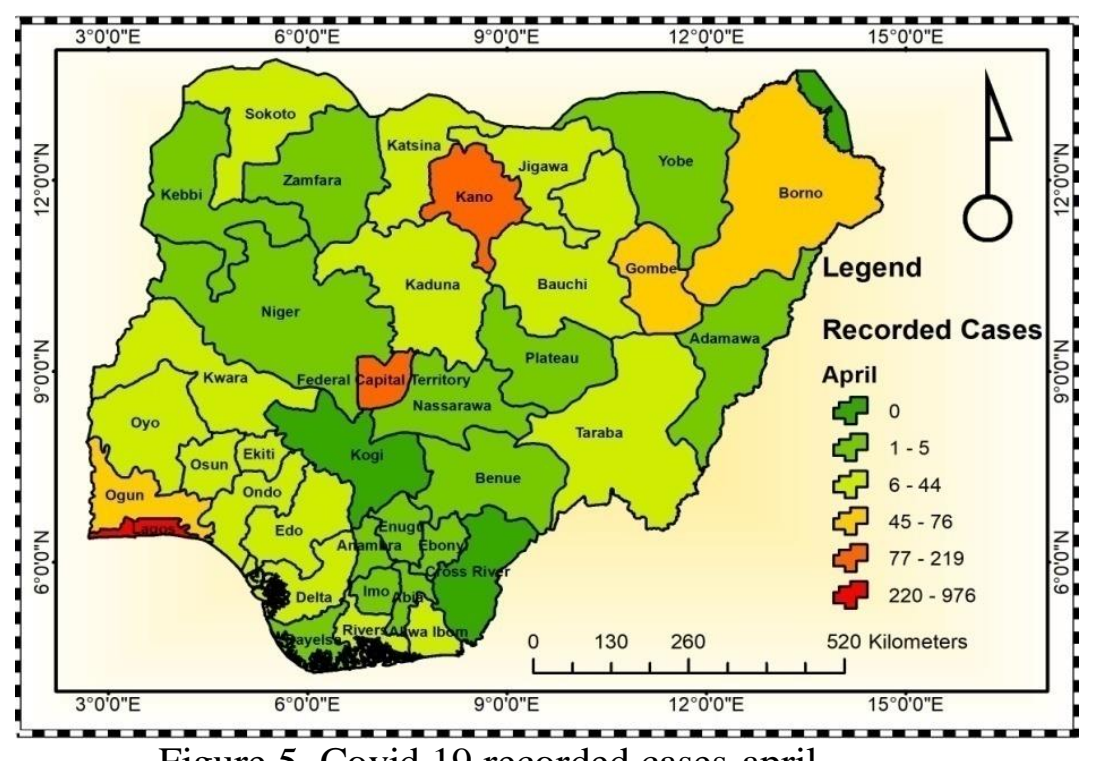

Figure 5. Covid 19 recorded cases-april

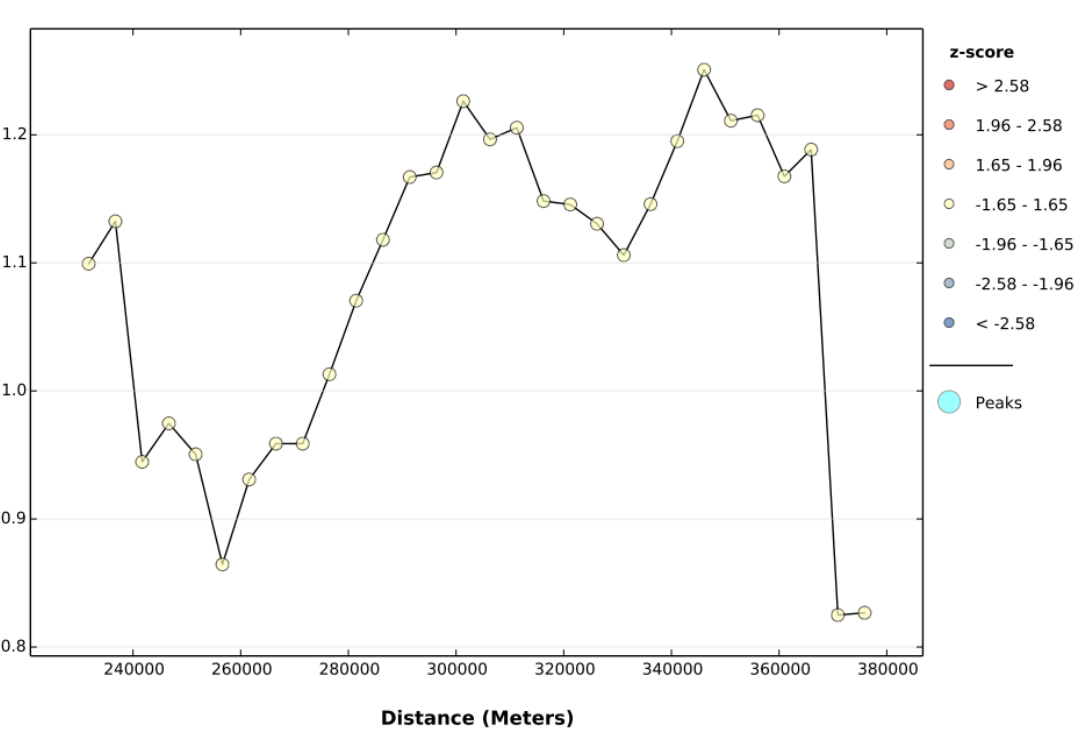

Figure 4. Spatial autocorrelation by distance-march

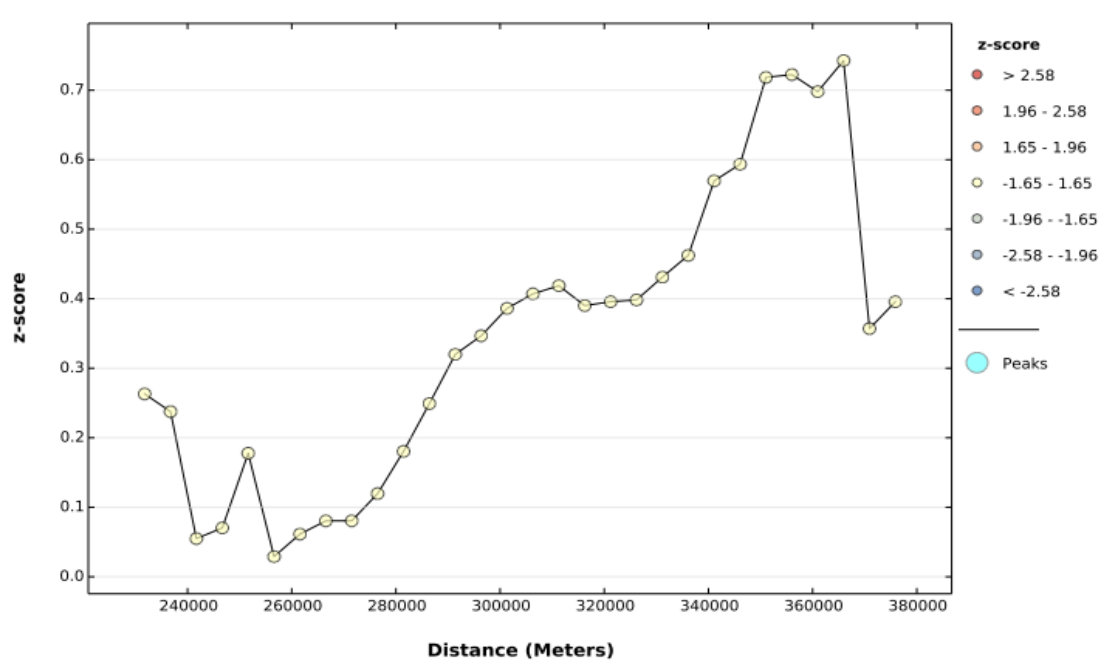

Figure 6. Spatial autocorrelation by distance-april 
Ifeyinwa Sarah Obuekwe et al. / Geosfera Indonesia 6 (1), 2021, 40-54

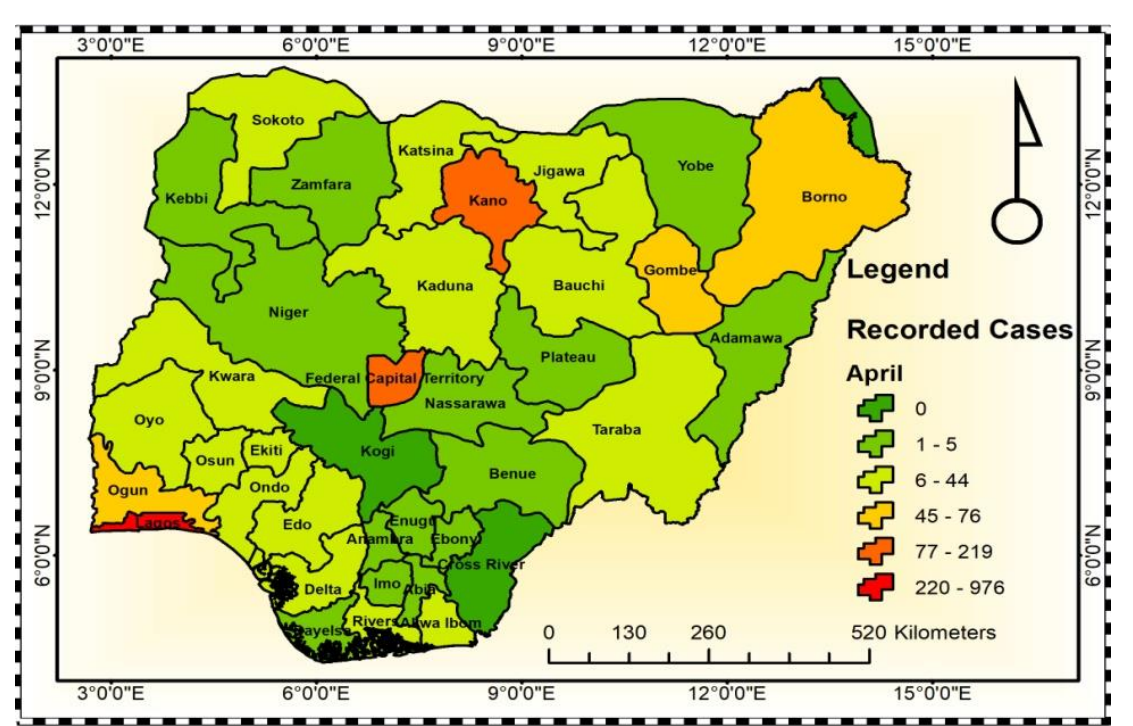

Figure 7. Covid 19 recorded cases-may

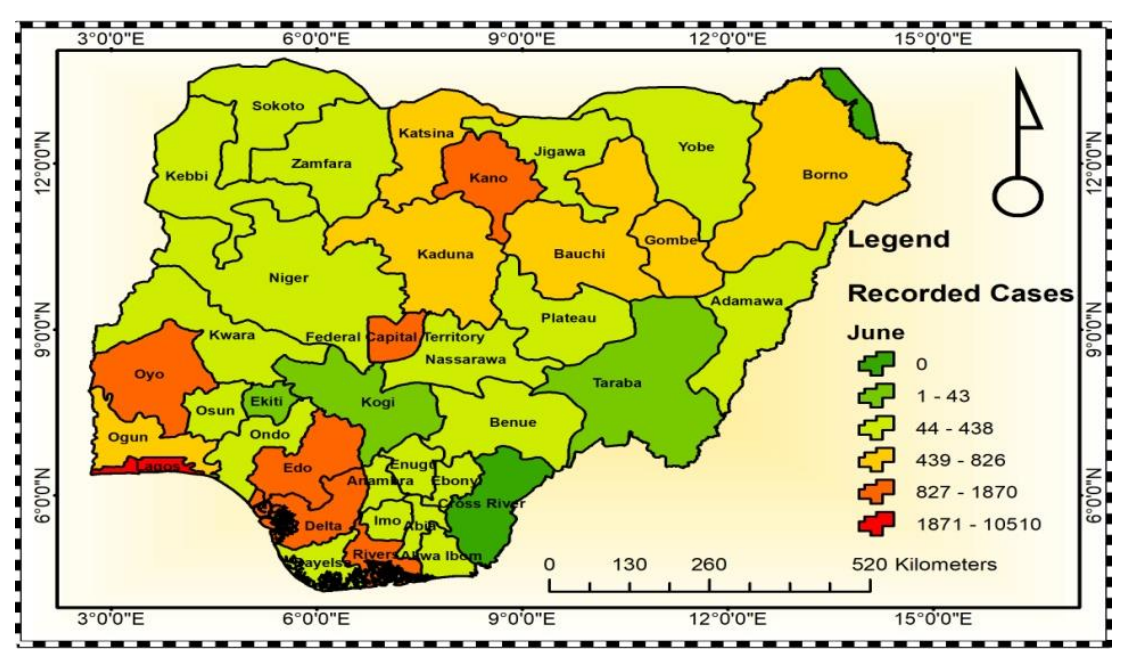

Figure 9. Covid 19 Recorded Cases-June

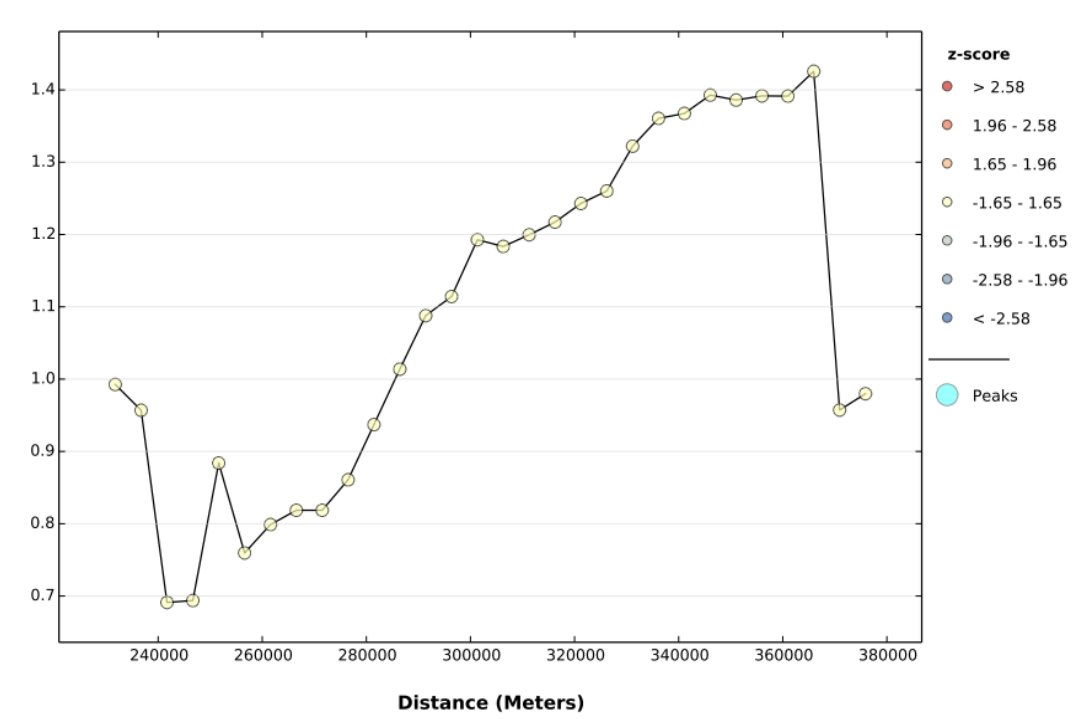

Figure 8. Spatial Autocorrelation by Distance-May

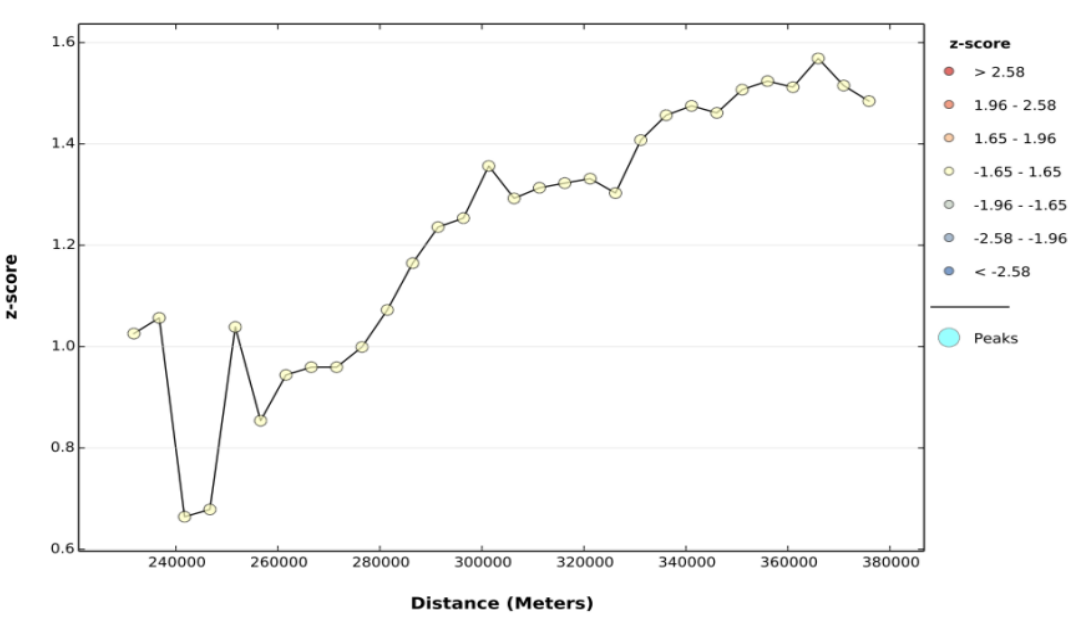

Figure 10. Spatial Autocorrelation by Distance-June 
Ifeyinwa Sarah Obuekwe et al. / Geosfera Indonesia 6 (1), 2021, 40-54

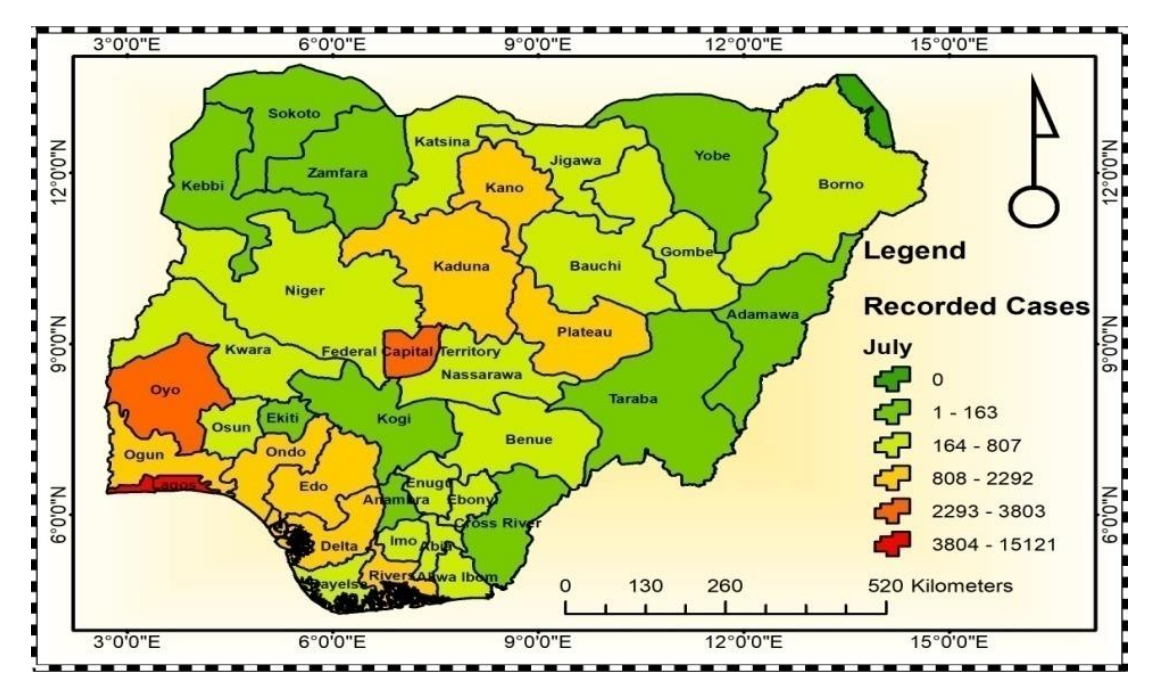

Figure 11. COVID 19 Recorded Cases-July

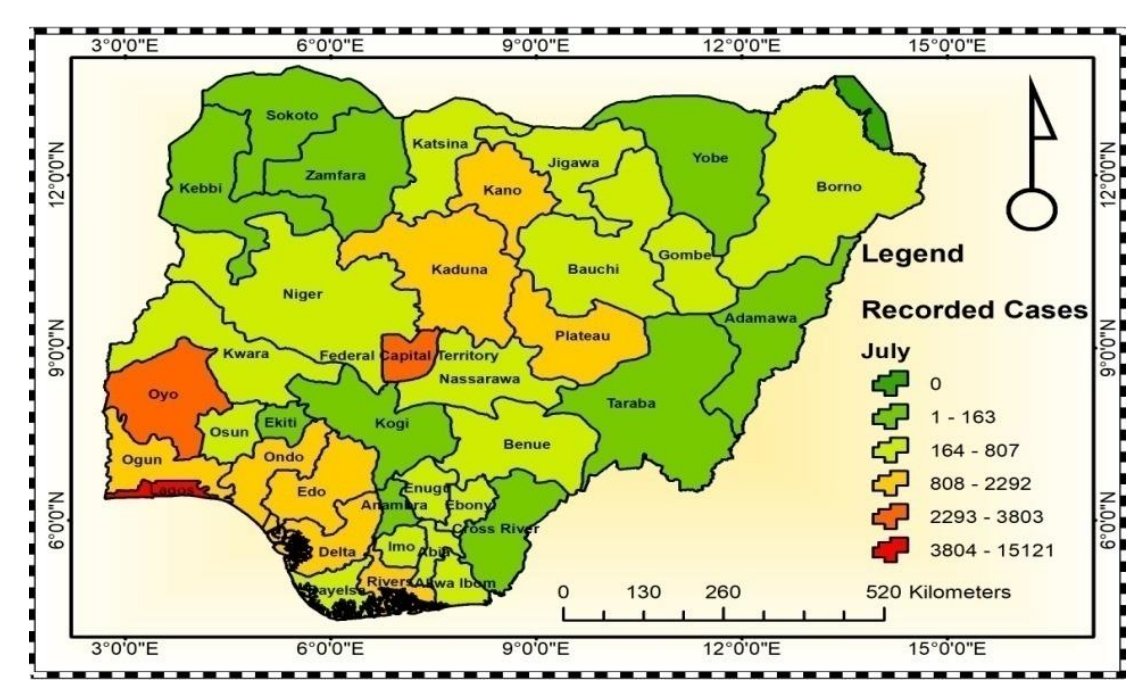

Figure 13. Covid 19 recorded cases-august

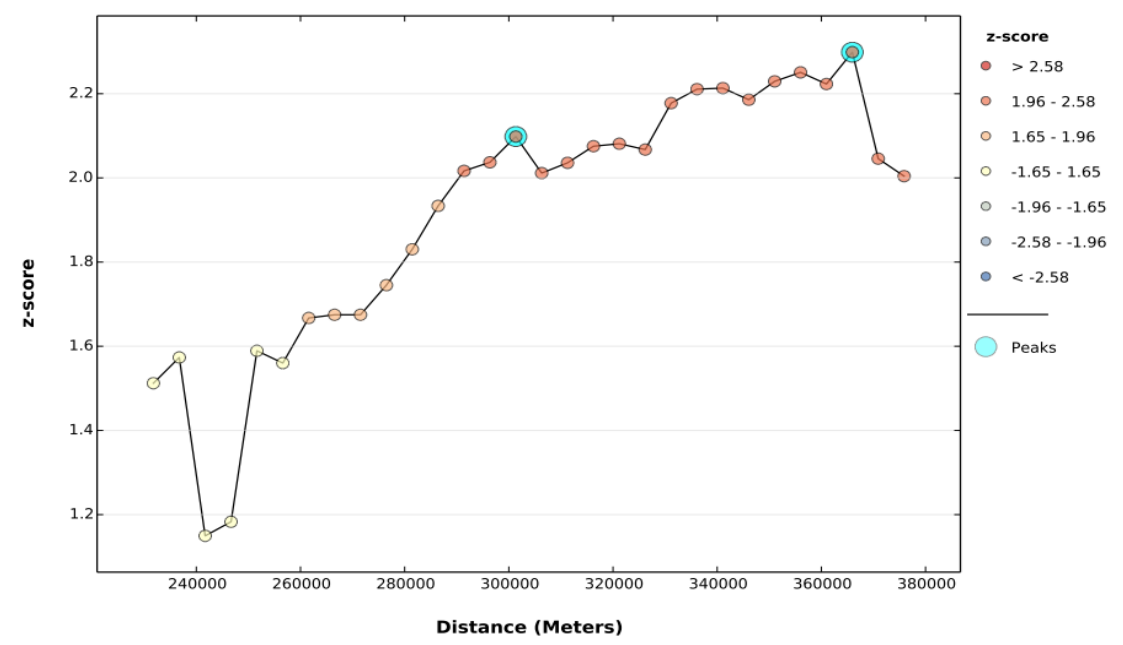

Figure 12. Spatial Autocorrelation by Distance-July

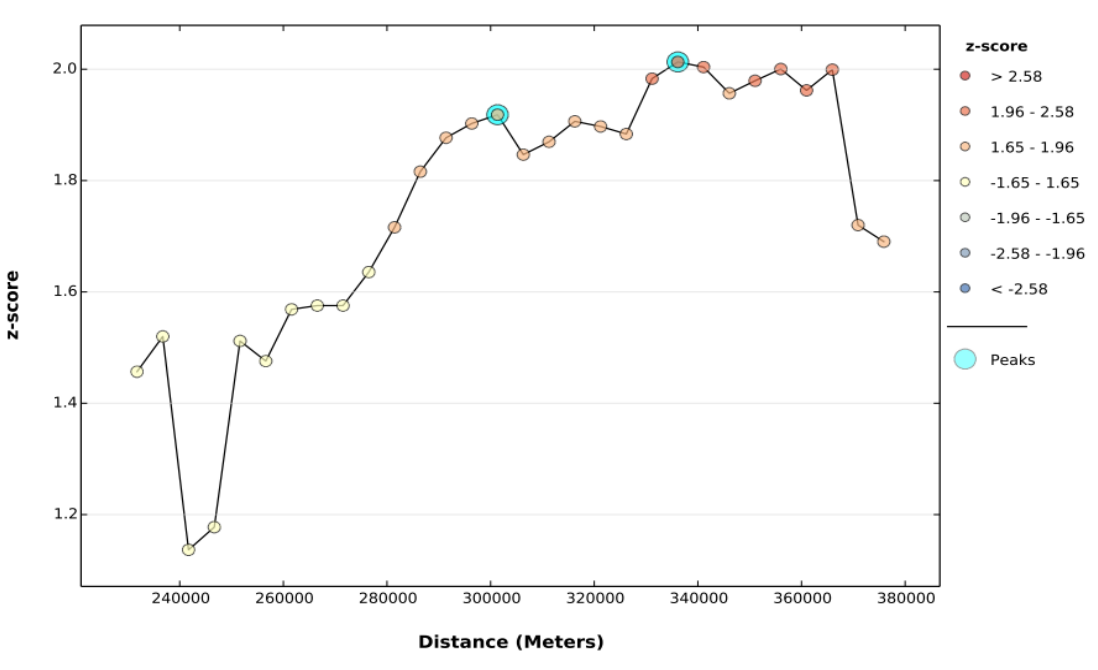

Figure 14. Spatial autocorrelation by distance-august 
Ifeyinwa Sarah Obuekwe et al. / Geosfera Indonesia 6 (1), 2021, 40-54

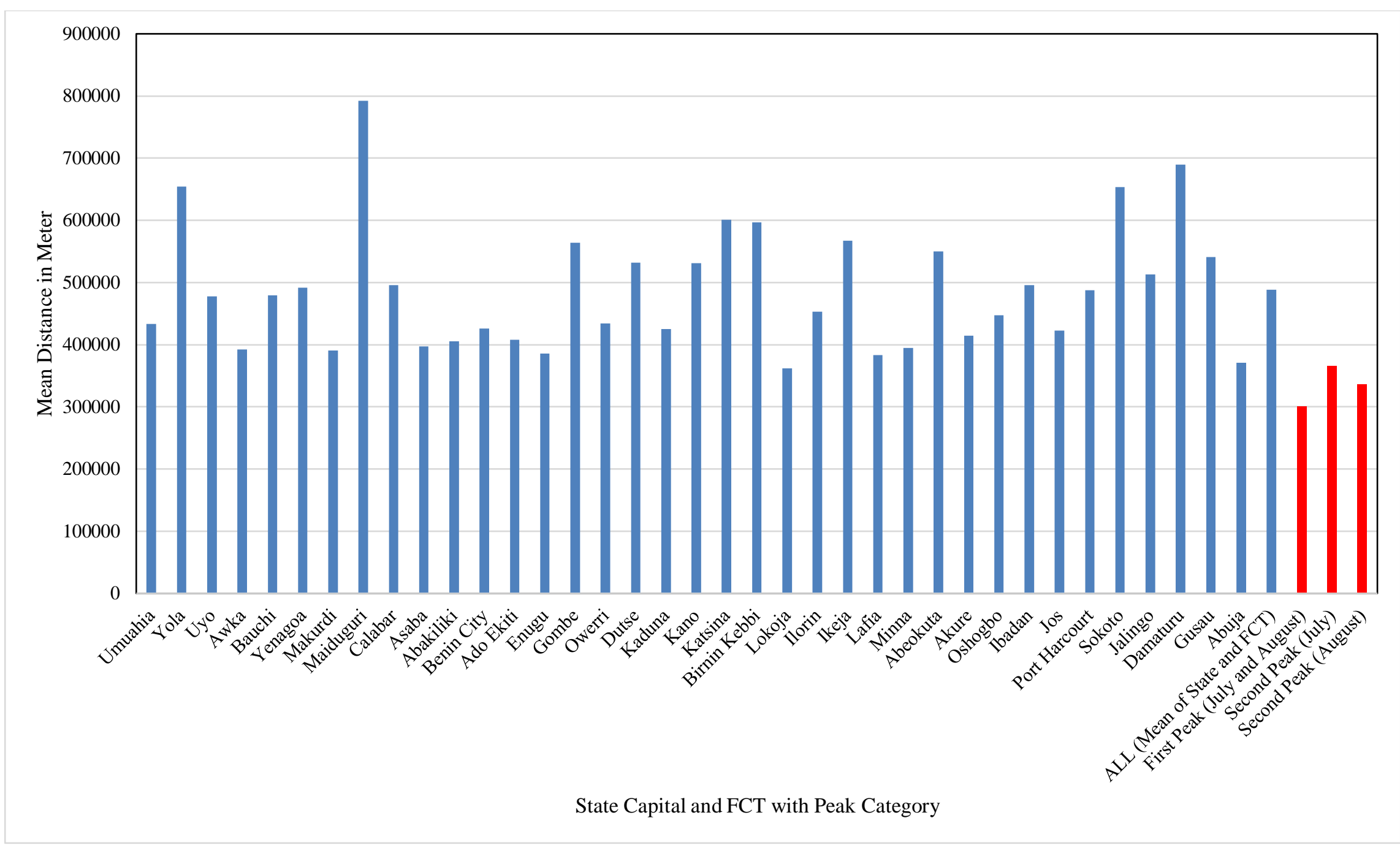

Figure 15. Mean distance of Nigeria State Capitals and the federal capital to other states capital and federal capital with peak category 
Ifeyinwa Sarah Obuekwe et al. / Geosfera Indonesia 6 (1), 2021, 40-54

Despite more visible clustering, the trend in the clustering of the COVID-19 over distance shows no significant peak from March to June (Figures 4, 6, 8, and 10). However, that of July and August exhibited patterns with two statistically significant peaks (Figure 12 and Figure 14). The first and second peak of July were 301,338.39 meter ( $\mathrm{Z}$ score $=2.098$; $\mathrm{p}<0.036)$ and $365,947.83$ meter $(\mathrm{Z}$ score $=2.299$; $\mathrm{p}=0.022)$ respectively while that of August were 301,338.39 meter $(\mathrm{Z}$ score $=1.918 ; \mathrm{p}=0.055)$ and 336,128.09 meter $(\mathrm{Z}$ score $=2.013$; $\mathrm{p}=0.044)$ respectively (Figure 12 and Figure 14).

The result shows that the mean distance of July and August's first peak was the same (301,338.39 meter). Therefore, the distance where the spatial processes responsible for clustering is the most pronounced was about 301,338.39 meter. Also, the second peak of August $(336,128.09$ meter) was less than that of July $(365,947.83$ meter). This implies that there was a significant drop in the mean transmission distance between July and August 2020. This was attributed to the fact that the spread has increased among neighboring state as more states recorded a similar range of COVID-19 cases.

Blank et al. (2016) used a similar approach, observed spatial clustering of bacterial canker severity, and showed that disease severity had significant spatial autocorrelation with dominant pattern recognized as clustered. A drop in mean transmission distance throughout foot-and-mouth outbreaks was similarly reported by Salje et al. (2016). Kiang et al. (2020) also found a significant spatial correlation associated with COVID-19 infections in China.

Each state capital and the Federal Capital had a mean distance of more than 300,000 meters to other states and federal capital (Figure 15). Although, only Yola, Maiduguri, Sokoto, and Damaturu have a mean distance above 600,000 meters (Figure 15). This is because these states are in the far north of the country, bordering the Niger Republic. Also, each of the state and the Federal Capital had a mean distance that is above the first and second peak of July and August except for Lokoja that has a mean distance (361,924 meters) that was less than the second peak of July $(365,947.83$ meters) (Figure 15). This implies that the interstate lockdown placed to curb the spread of COVID-19 was justifiable as any movement within the minimum and maximum significant peak distance can fast-track the spread of COVID-19. This corresponds with Salje et al. (2016) 's assertion, who claimed that a fundamental property of infectious disease dispersal is the average spatial distance between transmission-linked cases.

Although this study does not compare COVID-19 spread with population density nor socioeconomic activities. However, COVID-19 cases have been clustered around two states in Nigeria (Kano and Lagos). Moreover, this cannot be farfetched from the fact that Kano and Lagos happen to be the most populous states in Nigeria with vibrant industrial and 
commercial activities. Rapone (2020); Rocklöv \& Sjödin (2020) also pointed out that high population density and socioeconomic status are essential drivers of the spread of COVID-19. The disbelief regarding the presence of the virus also results in people taking preventive measures lightly. Even six months after the first case of coronavirus was reported in Nigeria, many Nigerians still doubt its existence (CSR-in-Action, 2020). Negligence could be detrimental to the spread to other states. Kiang et al. (2020) also reported that people with a history of travel in epidemic areas fail to isolate themselves on time, thus accelerating transmission risk. Thus, a study of this capacity that was able to showcase the significance of the temporal dynamics of COVID-19 can help guide decision-making regarding how a movement should be restricted to reduce the clustering phenomenon observed across Nigeria.

\section{Conclusion}

This study has shown that the point location of each state capital in Nigeria and recorded cases for each of the 36 Nigeria states and the Federal Capital Territory, Abuja displayed the significance of temporal dynamics in the mean transmission distance of recorded COVID-19 cases in Nigeria. This indicates that progression in the spread of the virus increased the spatial coverage of the virus while the distance of risk of exposure decreased. This information could be utilized to establish maximum movement restrictions to contain the spread of COVID-19 through lockdown as implemented by the Nigeria Government. This method can also be applied to well-detailed data and a small proportion of adequately collected data.

\section{Conflicts of Interest}

The authors declare no conflict of interest.

\section{References}

Alkhamis, M. A., Al Youha, S., Khajah, M. M., Ben Haider, N., Alhardan, S., Nabeel, A., ... Al-Sabah, S. K. (2020). Spatiotemporal dynamics of the COVID-19 pandemic in the State of Kuwait. International Journal of Infectious Diseases, 98(C), 153-160. https://doi.org/10.1016/j.ijid.2020.06.078.

Blank, L., Cohen, Y., Borenstein, M., Shulhani, R., Lofthouse, M., Sofer, M., \& Shtienberg, D. (2016). Variables associated with severity of bacterial canker and wilt caused by clavibacter michiganensis subsp. Michiganensis in tomato greenhouses. Phytopathology, 106(3), 254-261. https://doi.org/10.1094/PHYTO-07-15-0159-R. 
CSR-in-Action. (2020). The COVID-19 disbelief amongst the nigerian citizenry. Retrieved from https://www.csr-in-action.org/the-covid-19-disbelief-amongst-the-nigerian citizenry/.

Dhama, K., Khan, S., Tiwari, R., Sircar, S., Bhat, S., Malik, Y. S., ... \& Rodriguez-Morales, A. J. (2020). Coronavirus disease 2019-COVID-19. Clinical microbiology reviews, 33(4). https://doi.org/10.1128/CMR.00028-20.

Gayawan, E., Awe, O., Oseni, B., Uzochukwu, I., Adekunle, A., Samuel, G., ... Adegboye, O. (2020). The spatio-temporal epidemic dynamics of COVID-19 outbreak in Africa. Epidemiology and Infection. https://doi.org/10.1101/2020.04.21.20074435.

GIS Laboratory Geography Department. (2020). Map of Nigeria. Kano : Bayero University.

Kiang, M., Chin, E., Huynh, B., Chapman, L., Rodríguez-Barraquer, I., Greenhouse, B., ... Lo, N. (2020). Routine asymptomatic testing strategies for airline travel during the COVID-19 pandemic: a simulation analysis. The Lancet Infectious Diseases. https://doi.org/10.1101/2020.12.08.20246132.

Kim, S., \& Castro, M. C. (2020). Spatiotemporal pattern of COVID-19 and government response in South Korea (as of May 31, 2020). International Journal of Infectious Diseases, 98(C), 328-333. https://doi.org/10.1016/j.ijid.2020.07.004.

Kuwait Government Online. (2020) COVID-19 Updates, State of Kuwait. Retrieved from https://e.gov.kw/sites/KGOArabic/Pages/HomePage.aspx.

Marziano, V., Pugliese, A., Merler, S., \& Ajelli, M. (2017). Detecting a Surprisingly Low Transmission Distance in the Early Phase of the 2009 Influenza Pandemic. Scientific Reports, 7(1), 1-9. https://doi.org/10.1038/s41598-017-12415-2.

McKee, M., \& Stuckler, D. (2020). If the world fails to protect the economy, COVID-19 will damage health not just now but also in the future. Nature Medicine, 26(5), 640-642. https://doi.org/10.1038/s41591-020-0863-y.

Memish, Z. A., Cotten, M., Meyer, B., Watson, S. J., Alsahafi, A. J., Al Rabeeah, A. A., ... Drosten, C. (2014). Human Infection with MERS coronavirus after exposure to infected camels, Saudi Arabia, 2013. Emerging Infectious Diseases, 20(6), 10121015. https://doi.org/10.3201/eid2006.140402.

Moran, P. A. (1948). The interpretation of statistical maps. Journal of the Royal Statistical Society: Series B (Methodological), 10(2), 243-251.

Murray, C. J. (2020). Forecasting COVID-19 impact on hospital bed-days, ICU-days, ventilator-days and deaths by US state in the next 4 months. MedRxiv. https://doi.org/10.1101/2020.03.27.20043752.

National Bureau of Statistics (2011). Annual Abstract of Statistics. Abuja : National Bureau of Statistics.

Nigeria Centre for Disease Control (2020). COVID-19 Data. Retrieved from https://covid19.ncdc.gov.ng/. 
Okunade, S. K., \& Ogunnubi, O. (2019). The African union protocol on free movement: A Panacea to end border porosity? Journal of African Union Studies, 8(1), 73-91. https://doi.org/10.31920/2050-4306/2019/v8n1a4.

Prem, K., Liu, Y., Russell, T. W., Kucharski, A. J., Eggo, R. M., Davies, N., ... Klepac, P. (2020). The effect of control strategies to reduce social mixing on outcomes of the COVID-19 epidemic in Wuhan, China: a modelling study. The Lancet. Public Health, 5(5), e261-e270. https://doi.org/10.1016/S2468-2667(20)30073-6.

Rapone, C. (2020); Migrant Workers and the covid 19 Pandemic. United Nations Food and Agriculture Organization. Retrieved from http://www.fao.org/documents/card/en/c/ca8559en/.

Rocklöv, J., \& Sjödin, H. (2020). High population densities catalyze the spread of COVID19. Journal of Travel Medicine. https://doi.org/10.1093/jtm/taaa038/5807719.

Salje, H., Cummings, D. A. T., \& Lessler, J. (2016). Estimating infectious disease transmission distances using the overall distribution of cases. Epidemics, 17(C), 10-18. https://doi.org/10.1016/j.epidem.2016.10.001.

Scarpone, C., Brinkmann, S. T., Große, T., Sonnenwald, D., Fuchs, M., \& Walker, B. B. (2020). A multimethod approach for county-scale geospatial analysis of emerging infectious diseases: A cross-sectional case study of COVID-19 incidence in Germany. International Journal of Health Geographics, 19(1), 1-17. https://doi.org/10.1186/s12942-020-00225-1.

Teachout, M., \& Zipel, C., (2020). The economic impact of COVID-19 lockdowns in subSaharan Africa. Retrieved from https://www.theigc.org/wpcontent/uploads/2020/05/Teachout-and-Zipfel-2020-policy-brief-.pdf.

Wang, Y., Liu, Y., Struthers, J., \& Lian, M. (2021). Spatiotemporal Characteristics of the COVID-19 Epidemic in the United States. Clinical Infectious Diseases, 72(4), 643651. https://doi.org/10.1093/cid/ciaa934.

Woodhill, J (2020). Responding to the impact of covid-19 on rural people and food systems. Retrieved from https://www.foresight4food.net/wp-content/uploads/2020/05/Impactof-COVID-19-on-Rural-Poverty-and-Food-Systems-V2.pdf.

Worldometer (2020). Nigeria Population. Retrieved from https://www.worldometers.info/world-population/nigeria-population/.

Xie, Z., Qin, Y., Li, Y., Shen, W., Zheng, Z., \& Liu, S. (2020). Spatial and temporal differentiation of COVID-19 epidemic spread in mainland China and its influencing factors. Science of the Total Environment, 744(C), 140929. https://doi.org/10.1016/j.scitotenv.2020.140929.

Yang, F., Pahlavan, A. A., Mendez, S., Abkarian, M., \& Stone, H. A. (2020). Towards improved social distancing guidelines: Space and time dependence of virus transmission from speech-driven aerosol transport between two individuals. Physical Review Fluids, 5(12). https://doi.org/10.1103/PhysRevFluids.5.122501. 